\title{
Analysis of Organizational Culture: \\ A Critical Step in Mergers and Acquisitions
}

\author{
Suresh Gopalan \\ John E. Dittrich \\ West Texas A\&M University \\ Canyon, TX \\ Reed E. Nelson \\ Southern Illinois University at Carbondale \\ Carbondale, IL
}

\section{The Importance of Culture in Mergers and Acquisitions}

The 1980s witnessed an unprecedented wave of mergers and acquisitions. Greenberg (1989) estimated that 3,500 to 7,500 mergers and acquisitions have taken place in the last few years. Ironically, most of these mergers and acquisitions have ended with lowered financial performance and capital productivity, higher market-related risks, lower employee morale, high turnover, and a high degree of variance in performance. Similar conclusions were reached by McKinsey and Company in a study of 18 recent acquisitions (Lefkoe 1987), and in Knowles' (1988) analysis of mergers and acquisitions which concluded that seven out of ten acquisitions failed in the first ten years.

The American Management Association's 1988 study of 109 firms that were involved in either mergers or acquisitions found that "Mergers and acquisitions ... enable companies to streamline business activities, but frequently they create many problems that result in lesser productivity, market share, and profits" (Greenberg 1989). Results from this investigation revealed that thirty-six percent of the firms experienced high employee turnover, twenty-four percent had decreased profitability, and twenty-four percent reported losses in worker productivity. In many cases these factors caused a divestment of the acquired organization(Lev and Mandelker 1972; Rumelt 1974; Shrivastava 1985; Walter 1985).

A cultural mismatch between the acquiring and acquired organizations offers one explanation for this pattern of unfortunate consequences (Jemison and Sitkin 1986). The management of acquiring organizations often focuses on achieving a strategic and financial fit or accomplishing product synergy while neglecting issues of cultural compatibility (Burke and Jackson 1991; Cartwright and Cooper 1993; Mirvis and Marks 1992). Nahavandi and Malekzadeh (1988) comment: "With a few exceptions ... the role of sociocultural factors and the processes involved in merging two organizations as cultural entities have not been studied thoroughly." Schein (1992) concurs, observing that "Rarely checked, however, are those aspects that might be considered cultural: the philosophy or style of the company; its technological origins, which might provide clues as to its basic assumptions; and its beliefs about its mission and its future."

Early efforts to integrate or change incompatible cultures after an acquisition or merger have met with employee conflict, resistance, frustration, and turnover often leading to eventual divestiture of the acquired organization (Bastien 1987; Porter 1987; Sinetar 1981). 
In the acquisition of Intersil by General Electric, for example, GE made only one change in Intersil's operations. This change, however, was seen by employees as severely limiting the possibility for personal financial gain, and over one third of Intersil's managers and engineers left the firm (Magnet 1984; Trice and Beyer 1993). It is extremely important, therefore, for top management to gain insights about the culture of a firm which is the target of an acquisition or merger, well before the merger is consummated (Lefkoe 1987; Schein 1992; Shrivastava 1986).

Managers should note that while there is considerable consensus in the field that culture is important to organization effectiveness and success, there is much ambiguity and lack of precision regarding the operational definition of culture and consequently its measurement (Kotter and Heskett 1992; Rousseau 1990). Culture includes the behaviors, beliefs, attitudes, values, assumptions, shared by members of an organization and can be visualized as composed of many layers ranging from easy to observe artifacts, technology, and behaviors to hard to decipher assumptions. Culture, therefore, should be considered as a multidimensional, multilevel concept (Nahavandi and Malekzadeh 1988; Rousseau 1990; Schein 1992). Depending on their definition and methodology, scholars designate one or another of several possible layers as "culture" and relegate others as by-products or artifacts of culture (Cooke and Rousseau 1988; Kilmann et al 1986; Schein 1984). Despite multiple definitions associated with the culture construct, Rousseau (1990) considers the layers of culture associated with values, beliefs, and expectations as the primary elements of culture.

\section{The Need for Unobtrusive Pre-merger Cultural Diagnosis}

A pre-acquisition or pre-merger cultural diagnosis of the target company can provide management with valuable information to determine whether a proposed acquisition or merger should take place. Additionally, such an analysis may also provide management with insights helpful in developing successful post-acquisition/merger cultural change strategies and thus reducing post-acquisition/merger acculturative stress and failure. It is logical, then, to consider cultural diagnosis of the target organization as a necessary and significant step before any acquisition or merger process.

Acquisition activities are usually characterized by secrecy, confidentiality, and urgency, especially where more than one organization is interested in an acquisition (Bastien 1987; Ivancevich et al 1987; Walter 1985). Traditional methods of gathering information about organizational culture include ethnographic observation (Morgan and Smircich 1980), in-depth open-ended interviewing (Becker and Geer 1970), collecting and analyzing questionnaire responses from workers (Cooke and Rousseau 1988; Hofstede 1990), interpreting rites (Beyer and Trice 1983), and understanding symbols, ceremonies, and myths (Ouchi 1981). These methods are often quite time consuming, and compromise secrecy by requiring the cultural analyst to interact extensively with the organization to be acquired.

Important insights into an organization's culture, that is, its values, attitudes and beliefs, can be obtained from readily available data. Corporate annual reports, company sales catalogs, advertisements and product literature, Dun and Bradstreet, Standard and Poors, Moodys, popular business magazines such as Business Week, Fortune, Forbes, government reports, scholarly journals, and industry analysts are all potential sources of cultural 
information. Given the need for secrecy, we believe that these public sources of information offer an invaluable source of data which should be used to conduct a first-level, feasibility analysis of the merger or acquisition from a cultural perspective.

\section{Assessing Culture Strength and Content of the Target Organization}

We believe that two aspects of a target organization's culture are critical to management analysis. The notion of culture strength, introduced by Deal and Kennedy (1982), refers to the pervasiveness of a given set of norms, beliefs, and values in an organization. Kilmann, Saxon, and Serpa (1986) theorize that the strength of organizational cultures can range from very weak (diffused and non-pervasive) to very strong (widely held and shared). Strong cultures exert considerable pressure on organizational personnel to conform to established norms and prescribed patterns of behavior. The Hewlett Packard organization, in its published "The Hewlett Packard Way" philosophy, provides explicit guidelines for employee behavior. Strong cultures can also contribute significantly to organizational success or failure (Kotter and Heskett 1992). Again, Hewlett-Packard serves as an example of cultural support for continued success, as might the strong culture developed and reinforced in the Wal-Mart organization. IBM's strong culture, established early and reinforced through years of successful performance, has, however, also contributed to IBM's slow response to changes in its industry, and to its recent declining fortunes. In contrast, weak cultures are less influential in their impact on employees' values, beliefs, and norms and are largely inconsequential in shaping organizational outcomes.

Cultural content refers to actual norms, beliefs, values, and assumptions that are present in the organization. A review of the organization culture literature shows that organizations vary considerably in the values they espouse. Some have cultures emphasizing and encouraging creativity, flexibility, autonomy and adaptability (Trice and Beyer 1993). Other organizations have cultures displaying preference for authority, resistance towards change, and emphasis on stability. Still others stress excellence, competition, achievement, and winning (Deal and Kennedy 1982; Peters and Waterman 1982; Schein 1992).

\section{Measurement of Culture Strength}

From the work of Wilkins and Ouchi, several externally visible clues to the strength of an organization's culture are identified. They propose that a long history and stable membership, an absence of institutional alternatives, and interaction among members facilitate the emergence of strong cultures (Wilkins and Ouchi 1983). Operationally, these broadly described factors can be assessed by the following six indicators:

\section{Tenure of founder(s)}

The founder serves as the primary source of an organization's culture. According to Schein (1984), "An organization's founder ... by the sheer force of his or her personality, begins to shape the group's culture." In addition, where founders have remained at the helm for many years, strong cultures are likely to have developed. Lengthy tenure permits personal convictions, philosophies, and ideas of the founders to become deeply embedded in their respective organizations. Thomas Watson of IBM, Harley Proctor of Proctor \& Gamble, and 
William Kellogg of Kellogg Inc., were all founders with lengthy tenures who had lasting influences on their organization's culture. More recently, the late Sam Walton shaped an organizational culture which extends across hundreds of separate Wal-Mart retail stores (Kotter and Heskett 1992). Conversely, strong cultures are unlikely to develop in organizations where the founder or the founding group remained in control for only a brief period.

\section{Management by founder's family}

Culture strength is also enhanced by the number of family members occupying key management positions and the length of time that family hold such positions. Founders often appoint relatives as successors, a practice which will tend to reinforce and strengthen the cultural legacy. Tom Watson, Jr., for example, was outspoken in carrying forward and reinforcing the culture established by his father at IBM (Kotter and Heskett 1992). If the practice of appointing family members to key positions (as opposed to professional managers) is continued for an extended period, organizations will develop cultures that are strong, cohesive, and resistant to change. Kotter and Heskett (1992) mention the Coors family, as another example, which has continued through family management a long-standing (if frequently criticized) organizational culture established by the company's founder.

\section{Family ownership of stock}

From these examples of the effect of continued family domination (i.e.; Watson, Coors, Busch, and others cited by Kotter and Heskett 1992), it seems reasonable to expect that an organization is more likely to possess a strong culture when a significant percentage of stock is held by the founder and his/her family (or by the founding group and their families). When ownership and management are vested with the same group, owner-managers are in a unique position to promote their own ideas, interests, and preferred mode of functioning with little or no opposition. In the brewing industry, the Coors and Busch families continue to provide direction to their respective organizations after many decades of operation. Conversely, widely dispersed ownership and management by professionals makes it more difficult for any individual or group to make a strong impression on organizational culture.

\section{Employee turnover}

Low turnover enhances cultural strength by enabling members of one generation to pass on organizational values and beliefs to successive generations. This process affords a means for those cultural attributes to become institutionalized (Berger and Luckmann 1967). Organizations with lifelong employment practices, such as Lincoln Electric Company, tend to have low turnover rates and therefore a stable membership. The institutionalization of social knowledge does not occur in organizations with high turnover rates because brief employment periods do not lend themselves to internalization and transmission of the organizations' values and beliefs.

\section{Age of the organization}

The older the organization, the stronger is its culture, as cultural elements such as values, attitudes, and beliefs have had a longer time to be ingrained in employees through shared 
experiences (Schein 1984; Wilkins and Ouchi 1983). Organizations with long histories and stable memberships are characterized by a higher degree of socially shared knowledge, and consequently have stronger cultures.

\section{Single versus multiple locations}

The concentration of employees in one location facilitates extensive interaction and socialization and a process where shared values and beliefs (social knowledge) are "passed on" from one generation of employees to another. Social knowledge becomes institutionalized as "culture" when extensive interaction takes place among employees (Wilkins and Ouchi 1983). Thus, other things being equal, organizations that are located in a single geographic location are likely to have stronger cultures than those which are dispersed nationally or internationally (Kotter and Heskett 1992).

\section{The Impact of the Environment on Organizational Cultural Content}

For many years, organizational theorists have affirmed that organizations tend to be structurally responsive to the demands of their environments (Woodward 1965). While these studies did not examine organization-industry relationships from a cultural perspective per se, the results make it clear that organizations adapted to the needs of their environment by internalizing and displaying environmentally compatible characteristics (Aldrich 1979; Burns and Stalker 1961; Lawrence and Lorsch 1967). In the process of adapting to the environment, we would expect cultural elements from the environment to be assimilated by the organization (Trice and Beyer 1993).

Reynolds (1986) found empirical support for this idea in a study of 275 employees from five organizations on 14 aspects of organizational culture. These organizations were drawn from the computer services/software, franchised restaurants, and advanced technology industries. Reynolds observed that different industries spawn different organizational cultural characteristics. For example, those in the computer service/software industry displayed the least social conformity and a high cooperative work atmosphere; franchise restaurants reported the greatest task focus, the least risk taking, the highest social conformity; and centralized decision making; advanced technology firms had moderate social conformity, complex systems, and the greatest use of formal procedures. Reynolds (1986) concluded that (1) organizational cultures should be studied with reference to the industries from which they are drawn and (2) organizational cultures within the same industry will tend to display similar cultural characteristics.

Similarly, Gordon (1985; 1991) drew upon the work of Katz and Kahn (1966), Porter (1987), and other organizational theorists to suggest that organizations are affected by their industrial environment. The central premise of Gordon's $(1985 ; 1991)$ argument is that although organizational cultures are unique, industrial environments affect organizations causing their cultures to develop within certain parameters. Such parameters are based on industry-wide assumptions about environment, customer requirements, and competition resulting in shared common cultural characteristics within firms in the same industry. These cultural characteristics comprise the core of a company's values concerning the "right thing to do." Consistent with these values, management then develops strategies, structures, and 
processes that are necessary to conduct the business of an organization. In the following sections, industry characteristics are described from the competitive and customer aspects that affect the content of organizational cultures.

\section{Competitive Environment}

While presented in a number of different frameworks, three major factors are seen to have a significant affect on the nature of the competitive environment (Byars 1991; Day 1975; Mintzberg and Quinn 1991). They are:

a. The intensity of competition.

b. The rate of environmental change.

c. The extent to which the environment can sustain growth.

Competition and environmental change create uncertainty and volatility. Consequently, organizations respond by encouraging values and behaviors which help them to adapt to environmental demands. Organizations operating in dynamic environments with fierce competition (e.g., software companies) therefore, are likely to have highly responsive, adaptive, and aggressive cultures. Companies in industries with a high growth potential (e.g., medical bio-tech companies) are characterized by risk taking and innovative behaviors. Conversely, stable and predictable environments with little or no competition allow organizations to foster values and behaviors that institutionalize and standardize ways of conducting business. These organizations are likely to have cultures that are stable, conservative, and slow-changing with centralized structures. For example, utility companies face no direct competition and are frequently embedded in markets with stable growth potential. Consequently, the cultures within such companies are more likely to emphasize service, technical excellence, and efficiency over innovation and risk.

\section{Customer Requirements}

Customer buying preferences are seen by Gordon to determine the technology that organizations employ in dealing with their environments. These factors can be viewed as a single continuum ranging from a highly static marketplace with a demand for reliability to a highly dynamic marketplace with a demand for novelty. Organizations operating in the former environment are more likely to employ routine technologies compared to organizations in the latter environment which use advanced technologies. Organizations utilizing high level technologies encourage behavioral norms which emphasize achievement, encouragement of individual initiative, and action (Gordon 1991). These organizations allow their employees the greatest degree of freedom and independence, factors which are instrumental in developing creative, flexible, and innovative behaviors.

Companies utilizing routine sequential technologies (paper and glass industries for instance), develop norms which promote interdependence of people and organizational units, standardization of behaviors, deference to seniority, and deliberation when solving problems. In such organizations, speed and creativity are sacrificed for consistency and reliability. Thus, by analyzing the industry environment with respect to the number of competitors, the rate of environmental change, the degree of growth potential in the environment, and the nature of customer requirements, managers of acquiring companies can gain insights about 
industry-driven assumptions and consequently about the target company's principal cultural content.

\section{Are the Two Organizations Culturally Compatible?}

For a satisfactory analysis, the management of the acquiring firm should conduct a study of the strength and content of the culture of its own organization, as well as that of the target organization. Understanding one's own values system can go a long way in preparing for the potential clashes and difficulties which may be encountered in carrying out the merger (Lefkoe 1987). When the analysis is complete, the target organization's culture should be compared with that of the acquiring firm for similarities and differences. The strength of the culture of the target company could either be strong or weak, and its cultural content similar or dissimilar to that of the acquiring organization. The results of the diagnosis can then be placed into one of the alternative configurations created by the combination of these two factors.

From an acquirer's perspective we see four possibilities.

\section{Figure 1: Assessing Cultural Compatibility}

\begin{tabular}{|c|c|c|c|}
\hline & & $\begin{array}{l}\text { Cultural s } \\
\text { of the targ } \\
\text { organizati }\end{array}$ & \\
\hline & & Similar & Dissimilar \\
\hline $\begin{array}{l}\text { Cultural strength } \\
\text { of the target } \\
\text { organization }\end{array}$ & Weak & $\begin{array}{l}\text { Ideal } \\
1\end{array}$ & $\begin{array}{l}\text { Problematic } \\
2\end{array}$ \\
\hline & Strong & Desirable ${ }^{3}$ & $\begin{array}{l}4 \\
\text { Undesirable }\end{array}$ \\
\hline
\end{tabular}

Cultural fit, or compatibility, is considered to be ideal (Cell 1) when the culture of the target organization is diagnosed as weak in strength and similar in cultural content to the acquiring organization. For a variety of reasons (weak leadership, high turnover, geographic dispersion), organizations with weak cultures do not posses values, beliefs, and norms that are widely shared and strongly held. Consequently, members of the target organization are not likely to display a strong desire to preserve their own culture following an acquisition or merger. Resistance to change following an acquisition or merger, therefore, should be limited, sporadic, and basically inconsequential.

We consider degree of cultural compatibility to be problematic (Cell 2) when the target organization's culture is considered to be weak and dissimilar to that of the organization initiating the merger or acquisition attempt. The weakness of the target organization's culture 
reflects the possibility that employees may not have strongly internalized the organization's values. Thus, the assimilation of new values will not be strongly resisted. The lack of similarity between cultures, however, indicates that employees in the target organization have been socialized very differently, and may have a quite different view of their working world.

While the overall organization culture of the target organization may be "weak," subcultures may exist which are firmly embedded and not easily observed, especially by these unobtrusive measures. As mentioned earlier, cultures that are strong and dissimilar are hard to integrate. Strong and dissimilar subcultures will be no easier. Furthermore, if these subcultures are in areas operationally and strategically critical to the organization's success, then the task of post acquisition/merger acculturation becomes extremely complex, and of crucial importance. A more obtrusive analysis which might involve ethnographic analysis, focus group discussions, and intensive qualitative interviews would be needed to reveal the identity and/or nature of subcultures present in the target organization (Peters and Waterman 1982). We recommend that the more intensive cultural audit should probably be deferred pending further discussion and preliminary decisions on the general viability of the merger or acquisition. For these reasons, we consider the degree of cultural compatibility in Cell 2 as at best limited, and for practical reasons, problematic.

When the target organization's culture is diagnosed as strong and similar to the acquiring organization (Cell 3) we consider culture compatibility to be desirable (but not ideal) for the following reasons. Organizations with strong cultures have enduring values reinforced by strongly held beliefs and proud traditions which are widely shared by a majority of the employees. Employees in these organizations value their culture and are likely to demonstrate a strong desire to preserve these important aspects of their work life. Similarity in cultures between two organizations does not necessarily imply sameness. Each culture may possess subtle but unique patterns in the way relationships are conceptualized with customers, employees, and may have unspoken assumptions relating to performance, leadership practices, and ethics to guide everyday action. The acquiring organization can overcome resistance, build harmony and enhance cultural fit, however, by emphasizing common areas of cultural concordance between both organizations. In spite of the many challenges that are involved with the integration process under this scenario, success is possible with a suitable well developed acculturation strategy.

We consider cultural relationship between the two organizations to be undesirable when the target organization's culture is diagnosed as strong and dissimilar to that of the acquiring organization (Cell 4). As in Cell 3, employees working in organizations with strong cultures possess durable and widely held values and are likely to have a strong desire to preserve them. Employees in culturally dissimilar firms have different ideologies and value systems which are a consequence of differences in education, occupational habits, customers, suppliers, leadership, location and so on. Given that the cultures of the two organizations are dissimilar in content, it is unlikely that common core cultural areas can be found. Integrative measures which could be developed to enhance cultural fit, therefore, are not likely to be very effective (Ivancevich et al 1987).

Attempts to assimilate two strong, dissimilar organization cultures have almost always ended in failure (Magnet 1984; Shrivastava 1986). Therefore, when a target organization is 
diagnosed as possessing a strong and dissimilar culture, we suggest that the management of an organization initiating the acquisition or merger seriously consider the possibility of looking for a more suitable target, even though financial and market factors may be attractive.

\section{Cultural Change Strategies}

Framing a cultural change strategy before the actual acquisition or merger allows management of both organizations to anticipate challenges and difficulties involved in bringing two cultural entities together. This approach reduces the likelihood of arbitrary imposition of the acquiring company's culture, or neglect of issues likely to result in cultural conflict, a path of action which has caused the failure of many acquisitions (Sinetar 1981). Based on earlier diagnosis of the target organization's cultural strength, content, and degree of compatibility with the acquiring company, four modes of cultural change suggest themselves:

\section{Figure 2: Cultural Change Strategies}

\section{Cultural similarity \\ of the target \\ organization}

Similar

\begin{tabular}{|c|c|c|}
\hline Weak & $\begin{array}{r}\text { Assimilation } \\
1\end{array}$ & $\begin{array}{l}\text { Imposition } \\
\text { and Org. } \\
\text { Development } \\
2\end{array}$ \\
\hline Strong & $\begin{array}{r}3 \\
\text { Combination }\end{array}$ & $\begin{array}{l}4 \\
\text { Isolation and } \\
\text { Loose Coupling } \\
\quad \text { or } \\
\text { Liquidation }\end{array}$ \\
\hline
\end{tabular}

Cultural strength of the target organization

\section{Assimilation}

Assimilation is seen as an acceptable mode of cultural change when the degree of compatibility of the two organizations is diagnosed as "ideal." This situation exists when the target organization has a culture which is weak but similar to that of the acquiring firm (Cell 1). Assimilation involves a gradual replacement of the target organization's cultural components with the cultural values, beliefs, and organizational practices of the acquiring organization. Assimilation theorizes that the members of the acquired firm would willingly adopt the cultural practices of the acquirer due to their similarity and their desire to be associated with a "stronger" organization (Berry 1980; Sales and Mirvis 1984). At best, resistance to assimilation should be minimal, since employees in such organizations are not imbued with strong values or beliefs which they wish to preserve. 
The process of assimilation may also be facilitated by removing the entire top management of the acquired organization. William Agee and Alonzo McDonald, for example, were the CEO and President of Bendix Corporation respectively and were immediately removed from their offices by Edward Hennessey, Chairman of Allied Corporation soon after Allied acquired Bendix (Walter 1985). Trice and Beyer (1993) note that the removal of top executives makes it much easier for the acquiring firm to "introduce" their brand of culture by removing the locus of an existing subculture that might interfere with assimilation.

Cross-firm orientation programs and planned cross-firm rotational assignments for technical and managerial personnel can also aid in reducing uncertainty and improving cultural interchanges. As one example, an extensive retreat was conducted to help in clarifying and harmonizing the cultural differences observed during the H-P and Apollo merger (Mirvis and Marks 1992). Events after the post-retreat period showed that a gradual process of assimilation and integration was taking place because (a) both H-P and Apollo were in the same industry and their employees could relate to common technology, customers, and competitors, and (b) because each had faced similar problems such as competition from Sun and DEC (Mirvis and Marks 1992).

\section{Imposition and Organizational Development}

Imposition is the next mode of cultural change and is recommended when the object of acquisition is characterized by a weak and dissimilar culture (Cell 2). Imposition involves a comprehensive replacement of the acquired organization's culture especially when the culture contains elements that are considered as dysfunctional and unattractive from the acquirer's perspective. Under imposition, the acquired organization has a limited role in shaping and or affecting cultural, strategic and or operational decisions during and after the acquisition. Hewlett-Packard's acquisition of Apollo computer involved imposition, since a number of H-P policies were established at Apollo by directive (Mirvis and Marks 1992). Hewlett-Packard's planning and control systems, for example, were incorporated throughout Apollo. In addition, the manufacturing and sales functions were completely absorbed into Hewlett Packard's organization and policy framework.

Resistance to cultural change should be anticipated but in most cases may be ineffectual due to overall weakness in the acquiree's culture. In some instances, however, the overall weakness in the target organization's culture, may be the result of strong and antagonistic subcultures which are potential sources of resistance to change. In this situation, cultural "match" may be problematic, especially if these subcultures are found in organizationally valued occupations or functions.

Where the differences are seen as overly significant, but where the commercial gains are considered to be very attractive, a more intensive cultural audit of the target organization's culture using intensive focus group interviews with employees may be needed to identify cultural sources of resistance which can then be suppressed, eliminated, or transformed as the merger or acquisition proceeds. If further analysis reveals that strong and antagonistic subcultures are located in areas of strategic interest to the acquiring organization, we recommend that intensive organizational development strategies involving cross-company orientation or training assignments and conflict resolution techniques be employed to help 
in the cultural change process. While drastic, removal of subculture leaders can also be considered as one of several approaches to reducing the resistance of key subcultures. Consequently, imposition as a cultural change strategy should be considered only when the commercial or strategic gains are so attractive as to outweigh the cultural problems which will be encountered.

\section{Combination}

In Cell 3, where the acquiring organization has diagnosed the culture of the target company as strong, but similar to itself (a degree of cultural compatibility considered desirable), the suggested mode of acculturation is combination. Combination involves identifying and incorporating the core areas of common values into the value systems of the emerging organization so that resistance to change on the part of employees is minimized. The worst qualities of both cultures should be examined for ways to eliminate or reduce their negative impact on organizational performance. The best attributes of each should be retained and merged into a new culture which members of each organization can comfortably adopt. This cultural change strategy could be labeled a true acculturation strategy, since values from both organizations are adopted by the emerging organization (Berry 1980).

Good examples of this process and its results include the SmithKline-Beecham merger (Burke and Jackson 1991) and the merger of the Norfolk and Southern Railroads (Napier 1989). In the SmithKline-Beecham case, the focus was on creating a new and different culture, one which combined the positive qualities of both organizations while eliminating the negative qualities from both. An executive committee comprised of senior management from both organizations identified five primary values and nine leadership practices which were to be the basis of the organization's new culture. Traditional organizational development techniques were used to reduce intergroup conflict and the negativism in subcultures opposed to the merger. Planned cross-company familiarization activities reduced resistance brought about by a lack of knowledge on the part of employees and managers in both organizations. Other organizational development activities were tailored to meet the special needs of the two organizations involved. (For an extensive discussion of two merging organizations with strong, similar cultures, we suggest Burke and Jackson's (1991) account of the SmithKline and Beecham merger.) In the Norfolk \& Southern Railway merger, a new culture emerged as a result of combining names, locating the headquarters in a neutral city, cross-training key managers, and balancing representation on the board of directors (Napier 1989).

\section{Isolation and Loose Coupling or Liquidation}

In situations where the target company's culture is strong but dissimilar to that of the acquiring company and cultural compatibility viewed as Undesirable (Cell 4), isolation should be the preferred means of accommodation, if the acquisition or merger target is considered operationally attractive from a commercial perspective. An isolation strategy involves creating a structural configuration which results in cultural isolation of the target company. Under this "loose-coupling" strategy, some form of structural connection is made between the two organizations but with very little mutual cultural and behavioral exchange. 
The target company's employees are allowed to participate in their own cultural practices without intervention from the acquiring organization. This form of cultural accommodation is seen in acquired or merged firms which exist as wholly-owned but independently operated subsidiaries. These organizations arrange financial and operating linkages with the parent organization, but retain their original cultures and often their intact management teams (Magnet 1984).

In McGraw-Hill's acquisition of Standard \& Poors in 1966 and several other firms (four television firms, Datapro Research corporation, DRI) in the 1970's and 1980's, where these firms were not in the same industry as McGraw-Hill, the strength of the acquired firms' cultures and their strong market position contrasted with a relatively weak organizational culture at McGraw-Hill. In the ensuing years, the acquired firms functioned relatively autonomously within the loosely-coupled corporate framework, and continued to perform well (Kotter and Heskett 1992). Good results from this form of accommodation, but within the same industry, are reported in the Bank of America acquisition of Seattle First National. After a short period of corrective action, Seafirst operated with little change imposed by its acquirer, and became a strong contributor to Bank of America (Napier 1989).

Mergers that have ignored the vast cultural differences between the two firms (such as Federal Express and Tiger International Inc. merger) have experienced tremendous financial losses, lower stock price, the emergence of a 'we-they mentality' and poor morale among the employees (Tu and Sullivan 1994). When the cultural differences seem to be very pronounced, and where the principal strategic attractiveness of the acquired company lies in its resources, customers, federal and state tax benefits due to operating losses and assets, (rather than in its continued operation), the acquisition might ultimately call for a plan of liquidation. The acquisition by HCA of Botany Mills and the reorganization and liquidation of the operating textile company is one example of an acquisition undertaken wherein liquidation was deemed more strategically and financially attractive than a continuation of operations. A $\$ 15,500,000$ tax loss carry-forward was also a factor in this liquidation of the textile company ((Tompkins 1957). Botany subsequently was renamed Botany Industries, to reflect the broad range of its non-textile interests (New York Times 1959). Another example is the acquisition and subsequent liquidation of auto parts maker Sheller-Globe by Colonial Press, a printer of paperback books (Magnet 1986).

\section{Implications of Cultural Diagnosis and Assessment}

Performing cultural analysis not only has implications for suitable partner selection, but also embodies a proactive management approach in managing the human aspects of mergers and acquisitions, a factor that has been overlooked in most mergers and acquisitions (Cartwright and Cooper 1993). An initial assessment should attempt to compare the cultural strength (the intensity and concentration) and content (the substance) of both organizations to explore the degree of similarities and differences between them. This step is necessary because any decisions regarding cultural change are dependent on such an assessment. Once such an evaluation is complete, a list of possible acculturation strategies emerge. Two of the four cells (\#1 and \#3) appear to offer attractive opportunities where there is similarity in cultural content. In one of the two cells where cultural content is not similar and where strong 
subcultures may be present, (cell \#2), acquisition or merger prospects are considered much less attractive. In this situation, continued operations will call for significant attention to organizational development to address problems of conflict resolution or minimization. In the second case, in which cultures are strong and dissimilar (cell \#4), a formal separation of the two organizations is recommended to reduce or eliminate the opportunity for cultural dissonance.

This line of thinking suggests that mergers and acquisitions are probably most successful within one's own industry, where the content of the cultures of the two organizations may reflect the same environmentally-induced responses (Porter 1987; Shrivastava 1986). Where employees from two organizations, embedded in same or related businesses, share similar values and hold a common view of the world (markets, products, processes, technology), the degree of cultural compatibility is high. Consequently, cultural fit and integration can be maximized in such organizations following a merger or acquisition.

A similar contention is made in the organizational strategy literature regarding the success of intra-industry mergers on the one hand and the difficulties encountered by mergers which cross industry lines on the other (Kusewitt 1985; Shelton 1988; Singh and Montgomery 1987). Industry commonality in mergers and acquisitions is associated with superior performance and economic return while unrelated acquisitions have demonstrated higher risks and sub-par performance. While scholars examining strategy have attributed better financial returns in related mergers or acquisitions to synergies obtained through product, process, and market fits, they have not adequately recognized the importance of "cultural fit" and "cultural compatibility" as crucial factors for ensuring a successful outcome in a merger or acquisition.

Acquisitions and mergers between firms with strong cultures which operate in dissimilar environments are likely to have sustaining value only so long as they are considered a part of a financial "portfolio" of companies, and are isolated as independently operated subsidiaries (Magnet 1984). When the original management team departs (typically within 5 years) and is replaced by managers from the acquiring organization, the problems of cultural differences become quite evident (Shrivastava 1986). This pattern has been seen in mergers which formed conglomerates, many of which have fallen on very difficult times, and have subsequently divested themselves of the least similar subsidiary companies. Examples might include the merger of Westinghouse and Teleprompter (Business Week 1985) and Exxon and Vydec (Shrivastava 1986).

The divestiture of subsidiary companies following an unsuccessful merger and the loss of the key management team, has more than financial consequences for the acquiring firm and the target. The acquiring company typically suffers financially, and is burdened by management problems in the acquired unit which are unresponsive to the thinking of its management. For employees of the target company, their organization has been devastated by the loss of its long-standing leadership, by a lack of understanding on the part of the new corporate leadership, and by inept decisions in day to day operations (Bahn 1989; Ivancevich et al 1987). Uncertainty, the potential loss of one's job, and the real possibility of the demise of the entire organization are factors faced by all of those associated with the target company (Ivancevich et al 1987). Consequently, the cost of an unsuccessful merger or acquisition is clearly quite high.

With increasing demands for an organization to be "socially responsible," the liquidation approach (prescribed in cell \#4) may be counter-productive, especially in the short-run. 
Negative media reports regarding the adverse economic impact of plant closures on local communities can result in organized opposition, and pose serious public relations problems. Even where financial reasons may clearly justify liquidation or plant closure, organizations may face a high degree of political and social pressure to delay or to indefinitely postpone such decisions.

One must ask whether the social costs of liquidation or a failed merger or acquisition are reasonable, given the consequences described above. A more responsible solution to dealing with mergers and acquisitions where cultural problems seem likely to seriously interfere with the operations of a merged or combined organization would seem to be to find more ways to form a meta-organizational form, or network of associations, which preserves the identity, leadership, and culture of organizations while offering their associates the commercial value of their hard-earned expertise in dissimilar environments. These networks are increasingly observed in the formation of multinational enterprises, organizations where the cultural problems are not only caused by differences in companies and industries, but also by religions, nations, and national movements (Bartlett and Ghoshal 1991).

\section{References}

Aldrich, H. E. 1979. Organizations and Environments. Englewood Cliffs, NJ: Prentice Hall.

Bahn, Charles. 1989. "Surprise Endings to Takeovers." Across the Board (May): 39-44.

Bartlett, C. A. and S. Ghoshal. 1991. "Global Strategic Management: Impact on the New Frontiers of Strategy Research.” Strategic Management Journal 12: 14.

Bastien, David T. 1987. "Common Patterns of Behavior and Communications in Corporate Mergers and Acquisitions." Human Resource Management 26: 17-33.

Becker H. S. and B. Geer. 1970. Qualitative Methodology. Chicago: Rand McNally.

Berger P. L. and T. Luckmann T. 1967. The Social Construction of Reality. Garden City, New York: Anchor Books.

Berry J. W. 1980. "Social and Cultural Change." In H. C. Triandis \& R .W. Brislin (Eds.), Handbook of Cross-Cultural Psychology 5: 211-279, Boston: Allyn and Bacon.

Beyer, Janice M. and Harrison H. Trice. 1983. "How an Organization's Rites Reveal its Culture." Organizational Dynamics (Autumn): 5-24.

Burke, Warner W. and Peter Jackson. 1991. "Making the SmithKline Beecham Merger Work." Human Resource Management 20, 1: 69-87.

Burns, Tom and George Stalker. 1961. The Management of Innovation. London: Tavistock.

Byars, L.L. 1991. Strategic Management: Formulation and Implementation. Third Ed., New York: Harper Collins Inc. 
Cartwright, Susan and Cary L. Cooper. 1993. "The Role of Culture Compatibility in Successful Organizational Marriages." Academy of Management Executive 7, 2: 57-70.

Cooke, Robert A. and Denise Rousseau. 1988. "Behavioral Norms and Expectations: A Quantitative Approach to the Assessment of Organizational Culture." Group and Organizational Studies 13: 245-273.

Day. G. S. 1975. “A Strategic Perspective on Product Planning." Journal of Contemporary Business (Spring): 27.

Deal, Terrence and Alan Kennedy. 1982. Corporate Cultures: The Rites and Rituals of Corporate Life. Reading, MA: Addison Wesley.

“Do Mergers Really Work?" Business Week (June 3, 1985).

Gordon, George. 1985. "The Relationship of Corporate Culture to Industry Sector and Corporate Performance." In R.H. Kilmann. M.J.Saxton, R. Serpa \& Associates (Eds.). Gaining Control of the Corporate Culture. San Francisco: Jossey-Bass: 103-125.

-... 1991. "The Industry Determinants of Organizational Culture." Academy of Management Review $16,2: 396-415$.

Greenberg, R. E. 1989. “Measuring the Impact of Mergers and Acquisitions." Management Review (July): 54-56.

Hannan M. T. and J.H. Freeman. 1977.“The Population Ecology of Organizations." American Journal of Sociology 28: 926-964.

Hofstede, Geert. 1990. "Measuring Organizational Cultures: A Qualitative and Quantitative Study Across Twenty Cases." Administrative Science Quarterly 35: 286-316.

Ivancevich, John M., David M. Schweiger and Frank R. Power. 1987. “Strategies for Managing Human Resources During Mergers and Acquisition." Human Resource Planning. 10, 1: 19-36.

Jelinek, M., L. Smircich and P. Hirsch. 1983. "Introduction: A Code of Many Colors." Administrative Science Quarterly 28: 331-338.

Jemison, David and Sim Sitkin. 1986. "Corporate Acquisitions: A Process Perspective," Academy of Management Review 11, 1:145-163.

Katz, D. and R.L. Kahn. 1966. The Social Psychology of Organizations. New York: Wiley.

Kilmann, Ralph, Mary Saxton and Roy Serpa. 1986. "Issues in Understanding and Changing Culture." California Management Review 28, 2: 87-94.

Knowles, Robert. 1988. "Most Mergers Fail in 10 Years: Study." National Underwriter (April 25): 235-252. 
Kotter, John P. and James L. Heskett. 1992. Corporate Culture and Performance. New York: The Free Press.

Kusewitt, John B. 1985. “An Exploratory Study of Strategic Acquisition Factors Relating to Perfor mance." Strategic Management Journal 6: 151-169.

Lawrence, Paul R. and Jay W. Lorsch. 1967. Organization and Environment. Cambridge, Mass.: Harvard University Press.

Lefkoe, Morty. 1987. "Why So Many Mergers Fail.” Fortune(July 20): 113-114.

Lev, B. and G. Mandelkar. 1972. "The Microeconomic Consequences of Corporate Merger." Joumal of Business (January).

Magnet, M. 1984. “Acquiring Without Smothering.” Fortune (February 3): 22-30.

Magnet, M. 1986. "What Merger Mania Did to Syracuse." Fortune (February 3): 95-98.

Mintzberg, H. and J.B. Quinn. 1991. The Strategy Process: Concepts, Contexts, Cases. Second Ed., Englewood Cliffs, N.J.: Prentice Hall.

Mirvis, P. H. and M.L. Marks. 1992. "The Human Side of Merger Planning: Assessing and Analyzing Fit." Human Resources Planning 15, 3: 69-92.

Morgan, Gareth and Linda Smircich. 1980. "The Case for Qualitative Research." Academy of Management Review 5, 4: 491-500.

Nahavandi, Afsaneh and Ali R. Malekzadeh. 1988. "Acculturation in Mergers and Acquisitions." Academy of Management Review 13, 1: 79-90.

Napier, Nancy K. 1989. "Mergers and Acquisitions, Human Resource Issues and Outcomes: A Review and Suggested Typology." Journal of Management Studies 26, 3 (May): 271-289.

“Botany Asks New Name." 1959. New York Times(April 7).

Ouchi, William. 1981. Theory Z: How American Business Can Meet the Japanese Challenge. Reading, Massachusetts: Addison Wesley.

Peters, Tom and R.H. Waterman, Jr. 1982. In Search of Excellence: Lessons from America's Best-Run Companies. New York: Harper \& Row.

Porter, Michael. 1987. "From Competitive Advantage to Corporate Strategy." Harvard Business Review (May-June): 43-49.

Reynolds, Paul D. 1986. “Organizational Culture as Related to Industry, Position and Performance: A Preliminary Report." Joumal of Management Studies 23, 3: 33-345. 
Rousseau, Denise. 1990. "Assessing Organizational Culture: The Case for Multiple Methods" in Benjamin Schneider (ed.). Organizational Climate and Culture. San Francisco: Jossey-Bass: 153-192.

Rumelt, R. P. 1974. Strategy, Structure, and Economic Performance. Harvard Business School: Division of Research.

Sales, A. L. and P.H. Mirvis. 1984. "When Cultures Collide: Issues of Acquisition.". In J.R. Kimberly, \& R. E. Quinn (Eds.). Managing Organizational Transition. Homewood IL, Irwin: 107-133.

Schein, Edgar H. 1984. "Coming to a New Awareness of Organizational Culture." Sloan Management Review (Winter) 3-15.

Schein, Edgar H. 1992. Organizational Culture and Leadership. Second Edition, San Francisco: Jossey Bass.

Shelton, Lois M. 1988. "Strategic Business Fits and Corporate Acquisition: Empirical Evidence." Strategic Management Joumal 9: 279-287.

Shrivastava, Paul. 1985. "Integrating Strategy Formulation with Organizational Culture," Journal of Business Strategy 5, 3: 103-111.

Shrivastava, Paul. 1986. “Postmerger Integration.” Journal of Business Strategy 7, 1: 65-76.

Sinetar, M. 1981. "Mergers, Morale and Productivity." Personnel Journal 60: 863-867.

Singh, Harbir and Cynthia A. Montgomery. 1987. "Corporate Acquisition Strategies and Economic Performance." Strategic Management Journal 8: 377-386.

Tompkins, John S. 1957. “Trouble-Dodging Botany's ‘Secret”” New York Times (October 13).

Tu, Howard S. and Sherry E. Sullivan. 1994. "Federal Express: The Road to Globalization" in Peter Wright, Charles D. Pringle and Mark J. Kroll, Strategic Management. 4th. edition. Allyn-Bacon: Boston.

Trice, Harrison M. and Janice M. Beyer. 1993. The Cultures of Work Organizations. Englewood Cliffs, New Jersey: Prentice-Hall.

Walter, Gordon A. 1985. "Culture Collision in Mergers and Acquisitions" in P. J. Frost, L. F. Moore, M. R. Louis, C. Lundberg, \& J. Martin (Eds.), Organization Cultures. Beverly Hills, CA: Sage: 301-314.

Wilkins, Alan L. and William G. Ouchi. 1983. "Efficient Cultures: Exploring the Relationship between Culture and Organizational Performance." Administrative Science Quarterly 28: 468-481.

Woodward, J. 1965. Industrial Organization: Theory and Practice, London: Oxford University Press. 